\title{
Knowledge, Attitude and Practice of Mothers toward Children's Obligatory Vaccination
}

\author{
Heba Adel Ramadan ${ }^{1}$, Sahar Mohamed Soliman ${ }^{2}$, Rabab Gad Abd El-kader ${ }^{3}$ \\ ${ }^{1}$ B.Sc.N. Mansoura University, \\ ${ }^{2}$ Assist. Professor of Community Health Nursing, Faculty of Nursing, Mansoura University, Egypt. \\ ${ }^{3}$ Lecturer of community health Nursing Faculty of Nursing, Mansoura University, Egypt.
}

\begin{abstract}
Background: Vaccine preventable diseases (VPD) are considered one of the main causes of sicknesses and deaths among children all over the world, parents' knowledge and attitude towards immunization are likely influence uptake, vaccination is one of the most cost-effective public health tools to prevent infectious diseases. Objective: This study aimed to assess knowledge, attitude and practice of mothers' toward children's obligatory vaccination
\end{abstract}

Design: Cross-sectional survey was utilized; the study was conducted through mother's home visits at Damietta Governorate. The sampling method used was the cluster sampling approach promoted by the World Health Organization, Total number of the cluster was 30 clusters and 7 mothers from each cluster. The first house visited in each cluster was selected randomly according to availability of household list. Total number of mothers sample was 210 from 5 districts (1050 mothers). Four structured interviewing sheets were used to assess socio-demographic data, knowledge, attitude and practice of mothers toward obligatory vaccination. The data were analyzed using SPSS (Stand for statistical product and service solutions) version 16.

Results: revealed that there was a positive statistically significant correlation between knowledge and practice of the studied mothers.

Conclusion: less than half of the studied mothers had poor knowledge score while less than one third had good score, more than two thirds of the studied mothers had good attitude score while the minority had poor attitude score, and more than one third of mothers had good practice while one quarter had poor practice

Keywords: Attitude, Obligatory vaccination, Knowledge, Mothers, Parents, Practice,

\section{What is already known about the topic?}

- Vaccination is often cited as one of the most achievement of public health and the most cost effective intervention for child health promotion. However, this success has always been challenged by individuals and group factors.

What this paper adds?

- This paper provides insight about mothers' knowledge, attitude and practice scores toward their children's obligatory vaccination in Damietta Governorate.

\section{Introduction}

Immunization which has greatly reduced the burden of infectious diseases prevents illness, disability and death from vaccine preventable diseases including, Measles, Pertussis, Diphtheria, Polio, Rubella and Tetanus1 Immunizing a child significantly reduces costs of treating diseases, thus providing a healthy childhood and reducing poverty and suffering2.

World Health Organization (WHO, 2016) reported that 115 million infants worldwide received Diphtheria-Tetanus and Pertussis vaccine, there is about $85 \%$ of the world's children received one dose of measles vaccine, and received polio vaccine, however, remain the polio-endemic in two countries 3 (Afghanistan \& Pakistan). Immunization prevents an estimated two to three million deaths each year from Diphtheria, Tetanus, Pertussis (whooping cough), and Measles 4 According to the Unicef, (2014) 5. In Egypt, the estimated coverage rates of BCG (Bacilli Chalmette-Guerin, DPT3 (three doses of Diphtheria, Pertussis (whooping cough) and Tetanus, HepB3 (three doses of Hepatitis B vaccine), Measles vaccines, Pol3 (three doses of the Polio vaccine), Rubella, TT2 (two dose or more of Tetanus Toxoid vaccine) was ranged from 9698\% for children aged 18-29 months Immunity can be divided into active and passive immunity. Naturally acquired active immunity occurs when the person is exposed to a live pathogen, develops the disease 6; artificially acquired active immunity can be induced by a vaccine, a substance that contains the antigen 7 Artificially acquired passive immunity is a short-term immunization by the injection of antibodies, such as gamma globulin, that are not produced by the recipient's cells. Naturally, acquired passive immunity occurs during pregnancy; in which certain antibodies are passed from the maternal into the fetal 8. 
The attitude of most mothers towards immunization services is positive and relies on the efficacy of the vaccine to protect against disease; there was a poor attitude towards polio immunization among respondents who believe that it contains anti-fertility agents. Decision-making on immunization of a child lies predominantly on the father; and, if vaccination was rejected because of rumors and the priority accorded to parent's preference to more severe diseases 9 .

Mothers' knowledge, attitude and practice play an important role in achieving complete immunization before first birthday of the child, the previous parent factors are also contributing to success or failure of immunization program 10, knowledge attitude, and practice studies provide information about the people awareness of certain topics, their feelings and their practices 11.

\section{Aim of the study}

This study aimed to assess knowledge, attitude and practice of mothers toward children's obligatory vaccination.

\section{Subjects and Methods}

The study was conducted by mother's home visits at Damietta governorate. The sampling method used was cluster sampling approach promoted by the WHO, Total number of the cluster was 30 clusters and 7 mothers from each cluster. The first house visited in each cluster was selected randomly according to availability of household list. Total number of mothers sample was 210 from 5 districts (1050 mothers)

\subsection{Study design:}

A cross-sectional survey was utilized.

\subsection{Study Setting:}

The study was carried out at mother home in Damietta Governorate, Egypt, during the year 2015.

\subsection{Subjects:}

The researchers met and provided the potential participants with information about the study. Interviews were done to participated mothers in the study. Completed interview questionnaires by the researchers

\subsection{Data collection}

The survey interview questionnaires sought data relating to socio-demographic characteristics of mothers. The sheet includes age, education level, occupation, number of children. Knowledge levels toward children's obligatory vaccination include their source of knowledge about obligatory vaccination, types, benefits of vaccination and vaccination schedule. The respondents' knowledge was tested with 21 knowledge items which required true or false answers relating to diseases controlled by obligatory vaccination, importance contraindication and vaccination schedule with routes and doses. Correct answer scored= (1), while an incorrect answer scored $=(0)$. The respondents were divided into fair, poor and good groups evaluated as follows: poor $=$ less than $50 \%$ while from fair $=50-65 \%$ and Good $=$ more than $65 \%$ Attitude likert scale of children's obligatory vaccination consists of 16 statements with 3 point-scale (agree), (uncertain) and (disagree). The main categories of the attitude scale include importance of obligatory vaccination for children and its safety, side effects of vaccination and its effectiveness in prevention of communicable disease. Each subject was instructed to choose one of the three possible responses for each statement. Scoring system: scoring was as; agree $=2$, uncertain $=$ 1 and disagree $=0$ for the positive attitudes; while agree $=0$, uncertain $=1$ and disagree $=2$ for the negative attitudes. The total score of attitude ranged from 0-32. The attitude score was evaluated as; Poor $=$ less than $50 \%$, Fair $=50-65 \%$ and Good $=$ more than $65 \%$.

Practice tool was classified into 8 categories, composed of 13 questions. One mark was awarded for each correct answer, the total score of the practice ranged from 0 to 13 . The practice score was evaluated as follows; Poor $=$ less than $50 \%$, Fair $=50-65 \%$ score and Good $=$ more than $65 \%$.

\subsection{Pilot study}

A pilot study was conducted on (105) $10 \%$ of the studied mothers who were selected randomly from the mentioned settings and were later excluded from the main study sample to evaluate the clarity, applicability, reliability and to estimate time needed to fill in the research tools. On the basis of collected information, the necessary modifications were done, some questions were added and others were clarified or omitted.

\subsection{Statistical analysis}

SPSS software package (Stand for statistical product and service solutions version 16) was used for data analysis. Descriptive statistics including frequency, distribution, mean, and standard deviation were used to describe different characteristics. Chi-Square test was used to test the significance of results. Pearson correlation was conducted to show correlations between knowledge, attitude and practice scores among the studied 
mothers. p-value of less than 0.05 was considered as denoting statistical significance. Reliability of attitude questionnaire by Cronbach alpha test ( $\mathrm{r}$ alpha) were $=.778$.

\subsection{Ethical considerations}

An approval was attained from Research Ethnic Committee, Faculty of Nursing, Mansoura University, as well as an official permission were obtained from the director of each health unit in Damietta Governorate. An oral informed consent was obtained from each of the mothers who agreed to participate in the research after explaining the aim and the importance of the study. They were informed that they have the right to participate or not in the research. They were also assured about confidentiality of the obtained data and that they will be used for the research purpose only.

\section{Results}

Table (1): Represents that the studied mothers aged 18 to 55 years with a mean of $29.67 \pm 6.28,559$ $(53.2 \%)$ of the studied mothers were aged 20 to less than 30 years.

Concerning the family numbers $578(55 \%)$ of the families were composed of 1 to 4 members, while 472 (45\%) of mothers, families were composed of more than 4 members.

Concerning mothers, occupation the same table revealed that $850(81 \%)$ of the studied mothers were housewives and 1031 (98.2\%) of them were married.

Regarding to their level of education, the table shows that $625(59.5 \%)$ of the studied mothers had intermediate education and only $30(2.9 \%)$ of them had primary education

Table (2): shows that 462 (44\%) of the studied mothers had poor knowledge score while 328(31.2\%) had good knowledge score,

Table (3): shows that $735(70 \%)$ of the studied mothers had good attitude score, while the minority $6(0.6 \%)$ of them had poor attitude score,

Table (4): shows that $373(35.5 \%)$ of mothers had good practice score while $265(25.2 \%)$ of them had poor practice score.

Table (5): Reveals that $211(64.3 \%)$ of educated mothers with intermediate education and $91(27.7 \%)$ mothers with higher education had a good knowledge. As for source of information $161(49.1 \%)$ of the studied mothers who's acquired their information from health centers had a good knowledge. There were statistically significant associations between knowledge level and education and also with source of information ( $\mathrm{x} 2=89.201 \& 30.558$ respectively at $\mathrm{p}<0.001)$.

Table (6): shows that there were positive statistically significant correlations between mothers age and knowledge but it was a negative between age, attitude.

Table (1): Socio demographic data of the study participants $(\mathrm{n}=1050)$.

\begin{tabular}{|c|c|c|}
\hline Socio-Demographic data & No $=1050$ & $\%$ \\
\hline \multicolumn{3}{|l|}{ Age } \\
\hline$<20$ & 66 & 6.3 \\
\hline $20-<30$ & 559 & 53.2 \\
\hline $30-<40$ & 401 & 38.2 \\
\hline$\geq 40$ & 24 & 2.3 \\
\hline \multicolumn{3}{|l|}{ Number of family member } \\
\hline $1-4$ & 578 & 55.0 \\
\hline$>4$ & 472 & 45.0 \\
\hline \multicolumn{3}{|l|}{ Occupation } \\
\hline House wife & 850 & 81.0 \\
\hline Teacher & 55 & 5.2 \\
\hline Nurse & 85 & 8.1 \\
\hline Employee & 28 & 2.7 \\
\hline Student & 25 & 2.4 \\
\hline Engineer \&doctor & 7 & 0.7 \\
\hline \multicolumn{3}{|l|}{ Marital status } \\
\hline Married & 1031 & 98.2 \\
\hline Divorced/widow & 19 & 1.8 \\
\hline \multicolumn{3}{|l|}{ Education } \\
\hline Illiterate & 76 & 7.2 \\
\hline Primary & 30 & 2.9 \\
\hline Preparatory & 36 & 3.4 \\
\hline Secondary & 79 & 7.5 \\
\hline Intermediate & 625 & 59.5 \\
\hline Higher education & 204 & 19.4 \\
\hline
\end{tabular}


Table (2): Distribution of the studied mothers according to their general knowledge about obligatory vaccination and knowledge scores of the study participants $(n=1050)$.

\begin{tabular}{|l|l|l|}
\hline Characteristics & \multicolumn{2}{|l|}{} \\
\cline { 2 - 3 } $\begin{array}{l}\text { Importance of vaccination } \\
\text {-Prevent infectious diseases }\end{array}$ & $\mathbf{N}$ & \\
\hline -Maintain Child health & 980 & 93.3 \\
\hline - Reduce child mortality rate & 953 & 90.8 \\
\hline -Protect children from complication & 826 & 78.7 \\
\hline $\begin{array}{l}\text { Diseases controlled by obligatory vaccination } \\
\text {-Measles }\end{array}$ & 754 & 71.8 \\
\hline -Tuberculosis & & \\
\hline -Poliomyelitis & 963 & 91.7 \\
\hline -Diphtheria, Tetanus and Pertussis diseases & 890 & 84.8 \\
\hline -Hepatitis B virus & 1026 & 97.7 \\
\hline $\begin{array}{l}\text { Contraindication } \\
\text {-Malnutrition }\end{array}$ & 817 & 77.8 \\
\hline -Diarrhea & 601 & 57.2 \\
\hline -Minimal Infection & & \\
\hline -Seasonal flu & 208 & 19.8 \\
\hline -Immunological diseases & 671 & 63.9 \\
\hline the routes of vaccine administration & 328 & 31.2 \\
\hline $\begin{array}{l}\text { Doses of vaccines } \\
\text {-Polio }\end{array}$ & 542 & 51.6 \\
\hline - BCG(Bacillus-Calmette-Guerin) & 168 & 16.0 \\
\hline -DPT(Diphtheria, Tetanus and Pertussis) & 443 & 42.2 \\
\hline - HBV(Hepatitis B) & & \\
\hline MMR(Measles, Mumps and Rubella) & 404 & 38.5 \\
\hline Knowledge score & 426 & 40.6 \\
\hline Poor (<50\%) & 258 & 24.5 \\
\hline Fair (50 - 65 \%) & 239 & 22.7 \\
\hline Good (>65\%) & 258 & 24.5 \\
\hline
\end{tabular}

Table (3): Distribution of the studied mothers according to their attitude about obligatory vaccination and attitude score $(\mathrm{n}=1050)$

\begin{tabular}{|c|c|c|c|c|c|c|}
\hline \multirow[t]{2}{*}{ Characteristics } & \multicolumn{2}{|c|}{ Disagree } & \multicolumn{2}{|c|}{ Uncertain } & \multicolumn{2}{|c|}{ Agree } \\
\hline & $\mathbf{N}$ & $\%$ & $\mathbf{N}$ & $\%$ & $\mathbf{N}$ & $\%$ \\
\hline $\begin{array}{l}\text { Positive attitude } \\
\text { Vaccination is important }\end{array}$ & 3 & 0.3 & 12 & 1.1 & 1035 & 98.6 \\
\hline Vaccination is safe & 0 & 0.0 & 71 & 6.8 & 979 & 93.2 \\
\hline vaccination maintain child health & 5 & 0.5 & 24 & 2.3 & 1021 & 97.2 \\
\hline vaccination is the best for each infant & 7 & 0.7 & 31 & 3.0 & 1012 & 96.4 \\
\hline recommend others to vaccinate their children & 1 & 0.1 & 18 & 1.7 & 1031 & 98.2 \\
\hline Vaccination must give according to schedule & 3 & 0.3 & 26 & 2.5 & 1021 & 97.2 \\
\hline Vaccination save the community & 4 & 0.4 & 105 & 10.0 & 941 & 89.6 \\
\hline Effective in prevention of infectious diseases & 2 & 0.2 & 220 & 21.0 & 828 & 78.9 \\
\hline Vaccination reduce mortality rate & 7 & 0.7 & 264 & 25.1 & 779 & 74.2 \\
\hline Tetanus vaccine important for infant and mothers health & 7 & 0.7 & 90 & 8.6 & 953 & 90.8 \\
\hline $\begin{array}{l}\text { Negative attitude } \\
\text { Vaccines have severe side effects }\end{array}$ & 774 & 73.7 & 239 & 22.8 & 37 & 3.5 \\
\hline Infant Infected with the disease which immunized against & 628 & 59.8 & 359 & 34.2 & 63 & 6.0 \\
\hline Side effects cause death & 659 & 62.8 & 349 & 33.2 & 42 & 4.0 \\
\hline Vaccination important for boy than girls & 857 & 81.6 & 168 & 16.0 & 25 & 2.4 \\
\hline vaccination is harmful & 937 & 89.2 & 91 & 8.7 & 22 & 2.1 \\
\hline Attitude score & \multicolumn{3}{|l|}{$\mathrm{N}$} & \multicolumn{3}{|l|}{$\%$} \\
\hline Poor $(<50 \%)$ & \multicolumn{3}{|l|}{6} & \multicolumn{3}{|l|}{0.6} \\
\hline Fair $(50-65 \%)$ & \multicolumn{3}{|l|}{309} & \multicolumn{3}{|l|}{29.4} \\
\hline Good $(>65 \%)$ & \multicolumn{3}{|l|}{735} & \multicolumn{3}{|l|}{70.0} \\
\hline
\end{tabular}

Table (4): Distribution of the studied mothers according to their practice about obligatory vaccination and practice score $(n=1050)$

\begin{tabular}{|l|l|l|l|l|}
\hline Characteristics & No & \multicolumn{2}{l|}{ Yes } \\
\cline { 2 - 5 } & No & \% & No & $\%$ \\
\hline Your infant received vaccines according to Ministry of health schedule. & 24 & 2.3 & 1026 & 97.7 \\
\hline Reported vaccinations side effects & 59 & 5.6 & 991 & 94.4 \\
\hline -High temperature & 53 & 5.0 & 997 & 95.0 \\
\hline -Rash & 893 & 85.0 & 157 & 15.0 \\
\hline -Diarrhea & 827 & 87.8 & 223 & 21.2 \\
\hline
\end{tabular}




\begin{tabular}{|c|c|c|c|c|}
\hline -Pain & 456 & 43.4 & 594 & 56.6 \\
\hline Received anti-pyretic at vaccination day only. & 492 & 46.9 & 558 & 53.1 \\
\hline Received anti-pyretic after vaccination & 90 & 8.6 & 960 & 91.4 \\
\hline Swelling of the infant feet & 276 & 26.3 & 774 & 73.7 \\
\hline $\begin{array}{l}\text { Management of swelling } \\
\text {-Cold compress }\end{array}$ & 180 & 17.1 & 870 & 82.9 \\
\hline -Starch & 910 & 86.7 & 140 & 13.3 \\
\hline -Analgesic and local anti-inflammatory & 888 & 84.6 & 162 & 15.4 \\
\hline -Report doctor & 463 & 44.1 & 587 & 55.9 \\
\hline Practice score & \multicolumn{2}{|l|}{$\mathrm{N}$} & \multicolumn{2}{|l|}{$\%$} \\
\hline Poor $(<50 \%)$ & \multicolumn{2}{|l|}{265} & \multicolumn{2}{|l|}{25.2} \\
\hline Fair $(50-65 \%)$ & \multicolumn{2}{|l|}{412} & \multicolumn{2}{|l|}{39.2} \\
\hline Good $(>65 \%)$ & \multicolumn{2}{|l|}{373} & \multicolumn{2}{|l|}{35.5} \\
\hline
\end{tabular}

Table (5): Associations between mothers, knowledge score and demographic data $(\mathrm{n}=1050)$.

\begin{tabular}{|c|c|c|c|c|c|c|c|c|}
\hline \multirow{3}{*}{$\begin{array}{l}\text { Items } \\
\text { Socio-demographic data }\end{array}$} & \multicolumn{6}{|c|}{ Knowledge } & \multirow{3}{*}{$\chi^{2}$} & \multirow[t]{3}{*}{$\mathbf{P}$} \\
\hline & \multicolumn{2}{|c|}{$\begin{array}{l}\text { Poor } \\
(n=462)\end{array}$} & \multicolumn{2}{|c|}{$\begin{array}{l}\text { Fair } \\
(n=260)\end{array}$} & \multicolumn{2}{|c|}{$\begin{array}{l}\text { Good } \\
(\mathrm{n}=328)\end{array}$} & & \\
\hline & No & $\%$ & No & $\%$ & No & $\%$ & & \\
\hline \multicolumn{9}{|l|}{ Occupation } \\
\hline Not employed & 405 & 87.7 & 232 & 89.2 & 213 & 64.9 & \multirow[t]{2}{*}{$79.592^{*}$} & \multirow[t]{2}{*}{$<0.001^{*}$} \\
\hline Employed & 57 & 12.3 & 28 & 10.8 & 115 & 35.1 & & \\
\hline \multicolumn{9}{|l|}{ Education } \\
\hline Illiterate & 61 & 13.2 & 11 & 4.2 & 4 & 1.2 & \multirow[t]{6}{*}{$89.201^{*}$} & \multirow[t]{6}{*}{$<0.001^{*}$} \\
\hline Primary & 22 & 4.8 & 5 & 1.9 & 3 & 0.9 & & \\
\hline Preparatory & 21 & 4.5 & 12 & 4.6 & 3 & 0.9 & & \\
\hline Secondary & 36 & 7.8 & 27 & 10.4 & 16 & 4.9 & & \\
\hline Intermediate & 257 & 55.6 & 157 & 60.4 & 211 & 64.3 & & \\
\hline Higher education & 65 & 14.1 & 48 & 18.5 & 91 & 27.7 & & \\
\hline \multicolumn{9}{|c|}{$\begin{array}{l}\text { Source of information about } \\
\text { obligatory vaccination }\end{array}$} \\
\hline TV & 57 & 12.3 & 37 & 14.2 & 39 & 11.9 & \multirow[t]{7}{*}{$30.558^{*}$} & \multirow[t]{7}{*}{$0.001 *$} \\
\hline Radio & 1 & 0.2 & 0 & 0.0 & 1 & 0.3 & & \\
\hline Newspapers, school books & 9 & 1.9 & 9 & 3.5 & 23 & 7.0 & & \\
\hline Neighbours & 3 & 0.6 & 4 & 1.5 & 9 & 2.7 & & \\
\hline Health center & 213 & 46.1 & 125 & 48.1 & 161 & 49.1 & & \\
\hline TV and health center & 179 & 38.7 & 85 & 32.7 & 92 & 28.0 & & \\
\hline Health card & 0 & 0.0 & 0 & 0.0 & 3 & 0.9 & & \\
\hline
\end{tabular}

$\chi 2$ : Chi square test

*: Statistically significant at $\mathrm{p} \leq 0.05$

Table (6): Correlation between mothers' age, knowledge, and attitude and practice score

rs: Pearson coefficient

\begin{tabular}{|l|l|l|}
\hline \multirow{2}{*}{ Items } & \multicolumn{1}{|l|}{ Mothers' Age } \\
\cline { 2 - 3 } & $\mathbf{r}_{\mathrm{s}}$ & $\mathbf{P}$ \\
\hline Knowledge & 0.064 & 0.037 \\
\hline Attitude & $-.058^{*}$ & 0.060 \\
\hline Practice & $0.045^{*}$ & $0.145^{*}$ \\
\hline
\end{tabular}

*: Statistically significant at $\mathrm{p} \leq 0.05$

\section{Discussion}

Immunization has saved the lives of more children than any other medical intervention in the last 50 years. Vaccines are safe, simple and one of the most cost-effective ways to save and improve the lives of children worldwide12. Each year, two to three million lives are saved through immunization. However, more than 22 million children still go without basic immunization that leaving them susceptible to life-threatening illness and permanent disability. Immunizing children against vaccine-preventable diseases is an important factor in saving lives, increasing productivity, and alleviating poverty 13.

The present study results reveals that less than one third of the studied mothers had good knowledge score related to children obligatory vaccination and more than one third of mothers had good practice score, while more than two third of participants had good attitude score. The results of the current study may be due to the low level of awareness, lack of educational program in rural areas and their positive attitude toward vaccination may be due to that parents knew that vaccination was mandatory and required for school registration.

These finding were in agreement with several studies; This study done at Mawatch Goth, Kemari town, Karachi 14 to assess knowledge, attitude and practices of mothers regarding immunization of one-year old child 
this study revealed inadequate knowledge, strong positive attitude and limited practice of mothers. The other study carried in Peri-Urban Karachi 2 to assess mothers' knowledge about an Expanded Program of Immunization (EPI) and its relation with age-appropriate vaccination of infants which revealed that knowledge of studied mothers was inadequate. The results matched with study done in a Rural Area of North Kashmir, India to assess mothers' knowledge, attitude and practice about immunization of children 15 which illustrated good knowledge, good practice and good attitude of the studied mothers. . The same study was done in a traditional city in the United Arab Emirates16 and in Kosofe local Government area of Lagos state, Nigeria 17 which reported that good knowledge, positive attitude and good practice of mothers towards childhood immunizations Moreover other study was done in southwest Nigeria 18 to assess knowledge and perceptions of adult males towards childhood immunizations this results revealed good knowledge and good perceptions. However, Iraq study results 10 about parents' knowledge and practice regarding immunization related to pediatrics' immunization compliance revealed two third of parents' have adequate knowledge-practice scores. Which wasn't in the same line with the current study?

Regarding association between mothers, knowledge and sources of information about vaccination the present study revealed that there was a significant relationship this was in agreement with the study done in Kingdom of Saudi Arabia 19 which studied knowledge, attitude and practice of parents towards childhood vaccination revealed those whose source was TV showed higher significant total knowledge score $(p<0.001)$. Similarly, those whose source was internet showed higher significant total knowledge score $(\mathrm{p}<0.001)$. Parents whose source of information was journals/newspapers showed higher significant total knowledge score $(\mathrm{p}<0.049)$, and the study done in Yenepoya University, Mangalore, Karnataka, India by Jose, Roshni, and Nisha, 20 who studied awareness on immunization among mothers of under-five children showed that there was a significant association between knowledge and exposure to mass media in relation to immunization among mothers of under five children as the calculated value is more than the table value at 0.05 level of significance.

Source of information already differs in understanding from TV, health worker, books, media etc. Regarding association between education and knowledge, in my study there is a relation between knowledge and education, mothers with intermediate and higher education had good knowledge than those with primary and illiterate ones, the difference between mothers, knowledge and education was statistically significant. This finding was in agreement with the study done in Taif region, Saudi Arabia 21 which studied knowledge and attitudes on childhood vaccination, a survey among Saudi parents, and also the study done in southwest Nigeria 18 which founded statistically significant association between respondents' level of education and their willingness to support childhood immunization and also matching with study carried in Peri-Urban Karachi 2 to assess mothers' knowledge about an Expanded Program of Immunization (EPI) and its relation with ageappropriate vaccination of infants which revealed mother's knowledge is strongly associated with her educational status, which in turn is associated with father's educational status but disagree with the study done in Al-Beida City, Libya to assess Knowledge, attitude and practices of mothers regarding immunization of infants and preschool children 22 revealed there was no significant relation between immunization status and mothers' educational level.

According to association between mothers, education and practice the present study showed that there was a statistically significant relation between education and practice. This finding was in the same line with the result done in Minia City, Egypt, 23 about mothers' awareness and knowledge of under five years children regarding immunization they described association between giving vaccination at time and mother's education. It was found that nearly half of higher educated mothers gave vaccination at time compared with half of illiterate mothers who didn't give their children vaccination at time with highly statistically differences.

Lack of education, can lead to reduced ability to find, understand and use health information. Thus, education is an important determinant of health status in developing world; well educated mothers had better health than the poorly educated, furthermore, education may change mothers' knowledge and perception of the importance of modern medicine in the care of their children.

Regarding correlations between mothers' age and knowledge, practice score in the current study the difference between mother's knowledge, attitude and age was satisfactory significant. These findings are in the same line with the results done in peri-urban Karachi to assess mothers' knowledge about EPI and its relation with age-appropriate vaccination of infants which revealed the knowledge score was found to have a statistically significant association with age appropriate vaccine coverage of children. This correlation between age and knowledge could be justified as the knowledge level differs from younger than older, young mothers may be are interested to watching TV, media and reading books than older mothers. Older mothers differ from younger in a variety of physical/biological, psychological/mental and social dimensions. In some cases these age-related differences (whether normative or pathologic) are disadvantageous to the older because their performance is diminished relative to that of the younger ones. 


\section{Conclusion:}

\section{Conclusion \& recommendations}

Based on the findings of the present study, it could be concluded that:

- Less than half of the studied mothers had poor knowledge score, one third of the studied mothers had good knowledge score

- More than two third of studied mothers had good attitude score and more than one third of mothers had good practice.

- There were positive statistically significant correlations between mother's age and practice and the correlation between mothers, attitude and age was a negative one.

\section{Recommendation:}

- Health education campaigns about vaccination for mothers especially those in rural areas, slums, and villages emphasis on the less educated mothers.

- Immunization sessions should be held for mothers with children less than one year as well as social group meetings between mothers with children in the same age to exchange information at maternal and child health centers .

- Provide mothers with vaccination booklets explain the importance of vaccination and how to manage its side effects also continuous educational programs for mothers about the types and availability of others vaccination are not included in obligatory ministry of health vaccination schedule.

\section{Reference}

[1]. Yousif MA, Albarraq A.A, Abdallah M.A.A, \& Elbur A.I (2013): Parents' Knowledge and Attitudes on Childhood Immunization, J Vaccines Vaccin Taif, Saudi Arabia, 5: (1) :1-5

[2]. Siddiqi, N., Siddiqi, A.E., Nisar N \& Khan, A (2010): Mothers' knowledge about EPI and its relation with age-appropriate vaccination of infants in peri-urban Karachi. J Pak Med Assoc; 60(11):940-4

[3]. World Health Organization (2016)a: Immunization coverage, Available at http://www.who.int/mediacentre/factsheets/fs378/en/ Accessed on 23 March 2016.

[4]. World Health organization (2016)b: World Immunization Week 2016: Close the immunization gap, Available at http://www.who.int/campaigns/immunization-week/2016/en/ Accessed on 25/March/2016

[5]. UNICEF. (2014): Children in Egypt 2015: A statistical digest Available at www.unicef.org/egypt Accessed on 23 March 2016

[6]. Centers for Disease Control and Prevention (2014): Vaccines and immunization, Available at //http://www.cdc.gov/vaccines/vacgen/immunity-types.htm Accessed on 26/3/2016

[7]. Immunization advisory center (2012): The immune system and vaccination available at http://www.immune.org.nz/immune-systemand-vaccination accessed at 26 March2016

[8]. The Columbia Electronic Encyclopedia, (2012): Active and passive Immunity, Available at http://www.infoplease.com/encyclopedia/ science/immunity- active-passive-immunity. html Accessed on 1 June 2016

[9]. Falade \& Bankole, A. (2014): Vaccination resistance, religion and attitudes to science in Nigeria. un published thesis, p. 50

[10]. Qutaiba, B. et al, (2014): Are parents' knowledge and practice regarding immunization related to pediatrics' immunization compliance? a mixed method study, biomedcentra Pediatrics; 14(20) : 4-7.

[11]. Kaliyaperumal, K. (2004): Guideline for conducting a knowledge, attitude and practice (KAP) Study. Comm, Ophthalmol; 4:7-9.

[12]. Mereena \& Sujath, R. (2014): Study on Knowledge and Attitude Regarding Vaccines among Mothers of under-five Children attending Pediatric OPD in a Selected Hospital at Mangalore. Journal of Nursing and Health Science, 3: 39-46.

[13]. Paudyal, S. (2013): Knowledge, Attitude and Practice of Immunization Behaviour among Mothers Visiting Amda Hospital, Jhapa, Bhairahawa multiple campus, Faculty of Education, Tribhuvan University.

[14]. Nisar, N., Mirza, M., \& Qadri, M.H. (2010): Knowledge, Attitude and Practices of mothers regarding immunization of one year old child at Mawatch Goth, Kemari Town, Karachi. Pak J Med Sci; 26(1):183-186.

[15]. Hamid, S., Arshad, S., Fazli, A., \& Jabeen, R (2012): Immunization of Children in a Rural Area of North Kashmir, India: A KAP study, Journal of Health and Allied Sciences, 11, (1);

[16]. Bernsen, et al. (2011): Knowledge, Attitude and Practice towards Immunizations among Mothers in a Traditional City in the United Arab Emirates, Journal of Medical Sciences, 4(3): 114-121.

[17]. Abidoye, A.O. \& Odeyemi, K.A.(2013): Knowledge, Attitude and Practice of mothers to childhood immunization in Kosofe local government area of Lagos State, Nigeria, Anthonio Research Center, IJBAIR; 2(4): 66-72.

[18]. Agboola, M.S., Busari, A.O., Titilola, B., Olajide, J.T., \& Shabi, M.O et al, (2015): Knowledge, Attitude, Perceptions of Adu lt Males towards Childhood Immunizations in Southwest Nigeria, American, American Journal of Health Research, 3(1): 8-12 Published online January 23, 2015 (http://www.sciencepublishinggroup.com/j/ajhr)

[19]. Al-Zahrani, j. (2013): Knowledge, attitude and practice of parents towards childhood vaccination, Majmaah J Health Sciences, (1); 129-38.

[20]. Jose J., Roshni M., \& Nisha K., et al (2013): Awareness on immunization among mothers of under-five children, international journal of innovative research \& development, 2 (6); 621. Journal of Health Research, 3, (1); 8-12.

[21]. Elbur et al, (2014): Knowledge and attitudes on childhood vaccination a survey among Saudi parents in Taif region, Saudi Arabia, International Journal of Pharmacy Practice \& Drug Research; 4(2); 92-97.

[22]. Bofarraj, M. (2011): Knowledge, attitude and practices of mothers regarding immunization of infants and preschool children at AlBeida City, Libya., Egypt J Pediatr Allergy Immunol;9(1):29-34.

[23]. Ahmed, S.M., Abd-El Rahman, T.A.,\& Masoed, E.S (2013): Mothers' awareness and knowledge of under-five years children regarding immunization in Minia City Egypt, Life Science Journal;10:4 